\title{
Prevalence of self-reported disability, activity limitation and social participation in Sri Lanka
}

\author{
G V S Murthy ${ }^{1,2}$, E Schmidt ${ }^{3}$, C Gilbert ${ }^{2}$, S Varughese ${ }^{4}$, H B Pant ${ }^{1}$, P G Mahipala ${ }^{5}$, A P Abeydeera ${ }^{6}$ on \\ behalf the Sri Lanka National Blindness, Visual Impairment and Disability Steering Committee \\ and Survey Team ${ }^{7}$
}

\begin{abstract}
Introduction The World Health Organization estimates that $15 \%$ of the global population has a disability. Available evidence from Sri Lanka shows variable estimates of the magnitude of disability.

Objectives Determine the prevalence of self-reported disability in the adult population aged $\geq 18$ years, and associated risk factors in a nationally representative sample in Sri Lanka.

Methods The Washington Group short questionnaire was used to identify persons with self-reported disability. Data were collected from responsible adults aged $\geq 18$ years in the selected households. A four point-scale: "no difficulty", "some difficulty", "a lot of difficulty" and "cannot do at all" was used. Individuals screening positive for disability were administered an additional questionnaire on activity limitations, social participation and their health and financial concerns.
\end{abstract}

Results Overall 41.5\% (4131) [95\% Cl: 40.5-42.4] reported functional difficulty in at least one domain. The prevalence of disability, i.e. a lot of difficulty or cannot do at all was $3.8 \%$ (382) [95\% Cl: 3.5-4.2], while the prevalence of "some functional difficulty" was $37.6 \%$ (3749) [95\% Cl: 36.7-38.6].

The prevalence of disability increased with age and was higher among females, urban residents, and those with lower education and socio-economic status. Minor degrees of functional difficulties were more common among older people, females and people with lower education.

Conclusions The prevalence of disability and varying degrees of functional difficulty is high among the adult population of Sri Lanka. Evidence shows that a strategic plan is required to address the magnitude of disability and functional limitations in Sri Lanka.

Ceylon Medical Journal 2018; 63 (S2): s53-s60

DOI: http://doi.org/10.4038/cmj.v63i5.8743

\section{Introduction}

Current concepts of disability recognize the barriers 'created' by society in addition to the effects of an impairment or disease on an individual's activities and participation [1]. The preamble to the United Nations Convention on the Rights of Persons with Disability (UNCRPD) defines disability as an evolving concept and results from the interaction between persons with impairments and attitudinal and environmental barriers that hinder their full and effective participation in society on an equal basis with others [2].

This prompted the search for a valid universally acceptable definition which should be able to capture experiences across different types and grades of severity, across many areas of functioning, have flexibility to allow different uses including clinical or public health measurement and recognize the impact of the environment on persons with disability (PWD) [3]. The International Classification of Functioning, Disability and Health (ICF) provides a framework to measure these aspects and defines disability as "an umbrella term for impairments, activity limitations or participation restrictions which result

\begin{abstract}
${ }^{1}$ Indian Institute of Public Health, Hyderabad, India, ${ }^{2}$ Department of Clinical Research, London School of Hygiene and Tropical Medicine, ${ }^{3}$ Sightsavers UK, Haywards Health, West Sussex, UK, ${ }^{4}$ Regional Director, CBM South Asia Region, Bengaluru, India, ${ }^{5}$ Director General Health Services, Ministry of Health, Sri Lanka, ${ }^{6}$ Vision2020 Coordination Committee, Ministry of Health, Govt. of Sri Lanka, ${ }^{7}$ In addition to the above, other members of the Sri Lanka National Blindness, Visual Impairment and Disability Steering Committee and Survey Team: Champa Banagala, Kapila Edussuriya, KMK Gamage, Saman Senanayake, Ahamada Jeza,Sunil Fernando, Lakmini Dissanayake, Nirmi Vitharana, Nimal Edirisinghe, Sunil Settinayake, RP Kumara, SAHK Wimalarathne, Attapathu AH, Priyangani MD, Bandara KRTC, Chamin Rathnayake, YG Upali Jayarathne, Souvik Bandhopadhyaya, Mahesh Dorairaj, Sandeep Bhuttan.
\end{abstract}

Correspondence: GVSM, e-mail: <Gvs.Murthy@lshtm.ac.uk>. Received 19 February 2018 and revised version accepted 23 June 2018.

(i) This is an open-access article distributed under the terms of the Creative Commons Attribution License, which permits unrestricted use, distribution, and reproduction in any medium, provided the original author and source are credited. 
from an interaction between a person with a health condition and environmental factors (e.g. the physical environment, attitudes) and personal factors (e.g. age or gender") (Figure 1) [4].

Data on prevalence of disability is very important for planning programmes for persons with disability at local and national levels but available data shows wide variation with self-reporting during censuses showing figures of 1-2\% while the World Report on Disability reports a global prevalence of $15 \%$ [2]. This report also drew attention to the need for robust evidence to facilitate well-informed decisions for policy and programmes targeting people with disabilities (PWD) [5]. The Report categorically stated that impairment data are not an adequate proxy for disability and measures should be developed to obtain more comprehensive information on disability [2].

In the quest for an appropriate measurement tool for disability, a number of instruments have been developed. These include the 34-Item Disability Screening Questionnaire (DSQ-34) [6], the WHO Model Disability Survey (MDS) [7], the Iganga and Mayuge Demographic Surveillance System (IM-DSS) [8], the WHO Disability Assessment Schedule 2.0 (WHODAS 2.0) [9], the Rapid Assessment of Disability (RAD) tool [10] and the Key informant method using participatory rural appraisal [11].

The United Nations (UN) Statistical Division constituted a voluntary working group called the Washington Group (WG), representing different stakeholders including international statistical experts and international and national disability organizations to draft a universally acceptable definition of disability and methods to measure it [12]. The ICF provided the framework for developing these measures. This resulted in the development of a short set of six disability-related questions for six functional domains - seeing, hearing, walking, cognition, self-care and communication, suitable for use in national censuses and surveys which identifies a majority in the population experiencing limited or restricted participation in society [12]. The WG questionnaire translated disability concepts into measurement tools using a mixed-methods approach [13]. The WG questionnaire addresses the challenge of a disability definition and measurement in a culturally neutral and reasonably standardized manner [14]. Many countries have used the instrument both as a short or an extended set [15-19].

Available evidence from Sri Lanka shows variable estimates of the magnitude of disability. The Census 2001 estimated that $1.6 \%$ of the nation's population had a disability [20]. Data were also generated using a functionality definition in the World Health Survey, which included Sri Lanka over the period 2002-2004, and included the population aged $\geq 18$ years [21]. This survey reported $12.9 \%$ of adults had disability in Sri Lanka [2]. Recently the United Nations Economic and Social Commission for Asia and the Pacific (UN-ESCAP) conducted a Disability Survey using a functional definition of disability and estimated that the prevalence of disability among all-ages in Sri Lanka was $8.7 \%$ [22].

The literature suggests that disability is closely associated with poverty [23-25], and PWD have major barriers in accessing health services [26-28]. Therefore, information on the magnitude and socio-economic profile of persons with disability is of critical importance to plan and implement inclusive health and social services that benefit PWD, including those with visual impairment.

The National Blindness, Visual Impairment and Disability Survey was conducted in 2013-2014 in Sri Lanka. This paper presents the data on the prevalence of disability and varying degrees of functional difficulty in the adult population aged $\geq 18$ years.

\section{Methods}

The overall aim of the survey was to determine the magnitude and causes of blindness and visual impairment. As part of this survey, information was gathered to estimate the prevalence and causes of disabilities in adults aged $\geq 18$ years, living in enumerated households.

The blindness survey recruited a nationally representative sample of adults aged $\geq 40$ years; to estimate the prevalence of disability those aged $\geq 18$ years were included. All the nine provinces and 25 districts of Sri Lanka were included.

Based on an estimated prevalence of $25 \%$ for disability and functional difficulty based on the WG criteria of "some difficulty" in one or more of the six domains, $95 \%$ confidence intervals $(\mathrm{CI})$, a response rate of $80 \%$ and a design effect of 2 , the sample size required was approximately 2500 . It was anticipated that the sample size for blindness ( 6800 people aged $\geq 40$ years) would generate 2500 persons aged $\geq 18$ years from the enumerated households.

The study protocol was reviewed and approved by the Institutional Ethics Committees of the London School of Hygiene and Tropical Medicine, London, UK, the Faculty of Medicine, University of Colombo, Sri Lanka and the Indian Institute of Public Health, Hyderabad, India. Written informed consent was obtained from all participants at the time of enumeration and re-verified at the clinical examination site.

The WG short set (WGSS) was used to identify selfreported disability. All adults aged $\geq 18$ years in the selected households were eligible to be administered the WGSS. The WGSS was administered by trained investigators. These investigators were trained for one week on the administration of the questionnaire schedule and were 
also monitored while they administered the questionnaire schedules during the pilot study and during monitoring visits. The questionnaire schedules were translated into Sinhala and Tamil and were independently back translated into English to ensure accuracy of the translated versions. The questionnaire schedules were administered in the vernacular (Sinhala/ Tamil).

The short set of 6 questions was used to assess whether the respondent had difficulty in seeing, hearing, walking/climbing steps, remembering/concentrating, washing/dressing or communicating with answers given on a four point-scale: "no difficulty", "some difficulty", "a lot of difficulty" and "cannot do at all". The severity of self-reported functional difficulty/ disability was categorised based on the following responses: Some degree of functional difficulty: self-reporting of "some difficulty" in one or more domains. Disability: selfreporting of "a lot of difficulty" or the inability to undertake the activity in one or more domains.

Individuals who screened positive for disability or reported some degree of functional difficulty were then administered an additional questionnaire to elicit responses on activity limitations, social participation and the health and financial concerns.

A companion paper in this issue details the methodology used in the survey.

\section{Data analysis}

The data were analysed using STATA 13.0 (StataCorp LP, Texas, USA). Descriptive analyses and cross tabulations with calculation of Pearson chi squared tests were performed. Firstly, univariate analysis was done, to assess associations between socio-demographic factors and the risk of self-reporting functional difficulty or disability. The socio-demographic variables included age, sex, socio-economic status (SES), literacy status, place of residence, province of residence and ethnic group. Further analyses were undertaken using logistic regression. All tests are two sided, and the odds ratios (OR) and 95\% CI quoted are derived from logistic regression models.

\section{Results}

A total of 12,549 individuals were enumerated of whom $9965(79.4 \%)$ were available at home and responded to the WG short set. Some degree of functional difficulty in one or more domains was reported by $37.6 \%$ (3749) [95\% CI: 36.7-38.6] while 3.8\% (382) [95\% CI: 3.5-4.2] reported disability. Difficulty in seeing was the most frequently reported functional difficulty $(33.3 \%)$ and the second commonest disability (1.6\%). Difficulty in walking/ climbing stairs $(1.7 \%)$ was most frequently reported among those with disability and the second commonest for functional difficulty $(12.5 \%)$.

Overall 41.5\% (4131) [95\% CI: 40.5-42.4] reported some degree of functional difficulty (Table 1). For analysis, age was categorised as $<50$ years and $\geq 50$ years. The four quartiles of SES based on family assets was further categorised as 'lower' SES (lowest two quartiles of the SES scale) and 'higher' (top two quartiles of the SES Scale). Significant differences by age group, sex, place of residence, socio economic status and literacy status were observed both for functional difficulty and disability. The prevalence of disability increased with age and was higher among females, urban residents, and those from lower SES and poorer literacy (Table 1).

After adjusting for socio-demographic factors the following variables were significantly associated with disability: age, sex, place of residence, level of education and SES. Females were $40 \%$ more likely to report functional difficulty and $80 \%$ more likely to report disability compared to males. Those educated to secondary level and lower had 1.4 times higher risk of functional difficulty and 2.2 times higher risk of disabilities compared to those educated above secondary school level. Those residing in urban areas were two times more likely to report disability compared to people in rural areas; and those in lower socio-economic groups were 1.4 times more likely to report disability compared to their wealthier counterparts (Table 2).

Respondents reporting disability or functional disability were administered additional questions on social participation, barriers to performing regular activities and concerns about health issues. Respondents reporting disability experienced more barriers than those with some degree of functional difficulty (Table 3). One in five respondents with disability stated facing some or a lot of problems with social participation (74/361), while $10.8 \%$ (39/361) reported an effect of negative attitudes and actions from society (Table 3 ). $10.5 \%$ of those with disability also perceived that their disability had an adverse effect on the family finances (Table 3 ).

Visual acuity (VA) was measured for those aged $\geq 40$ years $(n=5739)$ and the level of agreement between objectively measured visual impairment (VI) and selfreported "difficulty in seeing even with glasses" was assessed. Among the 1,869 with any VI, 1277 (68.3\%) reported difficulty in seeing; when only those with severe VI or blindness were compared, the proportion increased to $84.1 \%$ (169/201). Among the 3,870 survey participants who were not visually impaired (distant vision) only 1684 $(43.5 \%)$ reported no problems in seeing (Table 4$)$. 
Table 1. Prevalence of self-reported disability among adults aged $\geq 18$ years

\begin{tabular}{|c|c|c|c|c|c|}
\hline \multirow[t]{2}{*}{ Parameter } & \multirow[b]{2}{*}{$N$} & \multicolumn{2}{|c|}{$\begin{array}{l}\text { Some difficulty in performing } \\
\text { activity (functional difficulty) }\end{array}$} & \multicolumn{2}{|c|}{$\begin{array}{l}\text { A lot of difficulty or cannot } \\
\text { perform activity (Disability) }\end{array}$} \\
\hline & & $N$ & $\%$ & $N$ & $\%$ \\
\hline Adults aged $18+$ years & 9965 & 3749 & $37.6 \%$ & 382 & $3.8 \%$ \\
\hline \multicolumn{6}{|l|}{ Age group } \\
\hline$<50$ years & 5342 & 954 & 17.9 & 80 & 1.5 \\
\hline \multirow[t]{2}{*}{$\geq 50$ years } & 4623 & 2795 & 60.5 & 302 & 6.5 \\
\hline & & \multicolumn{2}{|c|}{$\mathrm{X}^{2}-1900 ; \mathrm{p}<0.001$} & \multicolumn{2}{|c|}{$\mathrm{X}^{2}-170.4 ; \mathrm{p}<0.001$} \\
\hline \multicolumn{6}{|l|}{ Gender } \\
\hline Male & 4651 & 1439 & $30.9 \%$ & 142 & $3.1 \%$ \\
\hline \multirow[t]{2}{*}{ Female } & 5314 & 2310 & $43.5 \%$ & 240 & $4.5 \%$ \\
\hline & & \multicolumn{2}{|c|}{$\mathrm{X}^{2}-165.5 ; \mathrm{p}<0.001$} & \multicolumn{2}{|c|}{$\mathrm{X}^{2}-14.4 ; \mathrm{p}<0.001$} \\
\hline \multicolumn{6}{|l|}{ Residence } \\
\hline Urban & 1176 & 492 & $41.8 \%$ & 84 & $7.1 \%$ \\
\hline \multirow[t]{2}{*}{ Rural } & 8789 & 3257 & $37.1 \%$ & 298 & $3.4 \%$ \\
\hline & & \multicolumn{2}{|c|}{$\mathrm{X}^{2}-10.1 ; \mathrm{p}=0.001$} & \multicolumn{2}{|c|}{$\mathrm{X}^{2}-39.6 ; \mathrm{p}<0.001$} \\
\hline \multicolumn{6}{|l|}{ Socio economic status } \\
\hline Lower SES & 5389 & 2145 & 39.8 & 263 & $4.9 \%$ \\
\hline \multirow[t]{2}{*}{ Higher SES } & 4576 & 1604 & 35.0 & 119 & $2.6 \%$ \\
\hline & & \multicolumn{2}{|c|}{$\mathrm{X}^{2}-34.9 ; \mathrm{p}<0.001$} & \multicolumn{2}{|c|}{$\mathrm{X}^{2}-23.8 ; \mathrm{p}<0.001$} \\
\hline \multicolumn{6}{|l|}{ Literacy Status } \\
\hline Secondary school and lower & 2109 & 1176 & 55.8 & 184 & 8.7 \\
\hline \multirow[t]{2}{*}{ Beyond secondary school } & 7856 & 2573 & 32.7 & 198 & 2.5 \\
\hline & & \multicolumn{2}{|c|}{$\mathrm{X}^{2}-375.1 ; \mathrm{p}<0.001$} & \multicolumn{2}{|c|}{$\mathrm{X}^{2}-173.6 ; \mathrm{p}<0.001$} \\
\hline
\end{tabular}

Table 2. Association of disability and functional difficulty with socio-demographic parameters (adjusted analysis)

\begin{tabular}{|c|c|c|c|c|c|c|c|}
\hline \multirow[t]{2}{*}{ Parameters } & \multirow[t]{2}{*}{$N$} & \multicolumn{3}{|c|}{ Some degree of functional difficulty } & \multicolumn{3}{|c|}{ Disability } \\
\hline & & $N(\%)$ & Adj. $O R$ & $95 \% C I$ & $N(\%)$ & Adj. $O R$ & $95 \% C I$ \\
\hline \multicolumn{8}{|l|}{ Age group } \\
\hline$<50$ years & 5342 & $954(17.9)$ & Ref & & $80(1.5)$ & Ref & \\
\hline$\geq 50$ years & 4623 & $2795(60.5)$ & 6.6 & $5.9-7.3$ & $302(6.5)$ & 3.2 & $2.5-4.1$ \\
\hline \multicolumn{8}{|l|}{ Sex } \\
\hline Male & 4651 & $1439(30.9)$ & Ref & & $142(3.1)$ & Ref & \\
\hline Female & 5314 & $2310(43.5)$ & 1.8 & $1.7-2.0$ & $240(4.5)$ & 1.4 & $1.1-1.7$ \\
\hline \multicolumn{8}{|l|}{ Residence } \\
\hline Rural & 8789 & $3257(37.1)$ & Ref & & $298(3.4)$ & Ref & \\
\hline Urban & 1176 & $492(41.8)$ & 1.2 & $1.0-1.4$ & $84(7.1)$ & 2.1 & $1.6-2.7$ \\
\hline \multicolumn{8}{|c|}{ Socio economic status } \\
\hline Higher SES & 4576 & $1604(35.0)$ & Ref & & $119(2.6)$ & Ref & \\
\hline Lower SES & 5389 & $2145(39.8)$ & 1.03 & $0.9-1.1$ & $263(4.9)$ & 1.4 & $1.2-1.8$ \\
\hline \multicolumn{8}{|l|}{ Literacy status } \\
\hline Beyond secondary & 7856 & $2573(32.7)$ & Ref & & $198(2.5)$ & Ref & \\
\hline$\geq$ Secondary & 2109 & $1176(55.8)$ & 1.4 & $1.3-1.6$ & $184(8.7)$ & 2.2 & $1.7-2.7$ \\
\hline
\end{tabular}

SES = socio-economic status 
Table 3. Reported difficulty in social participation, activities and health concerns, by level of functional difficulty and disability

\begin{tabular}{|c|c|c|c|c|c|c|c|c|}
\hline \multirow{3}{*}{$\begin{array}{l}\text { Difficulty in past } 30 \text { days } \\
\\
\text { Social participation \& activities }\end{array}$} & \multicolumn{4}{|c|}{$\begin{array}{l}\text { Some degree of functional difficulty } \\
\qquad(N=3649)\end{array}$} & \multicolumn{4}{|c|}{$\begin{array}{l}\text { Respondents reporting disability } \\
\qquad(N=361)\end{array}$} \\
\hline & \multicolumn{2}{|c|}{ Some difficulty } & \multicolumn{2}{|c|}{ Lot of difficulty } & \multicolumn{2}{|c|}{ Some difficulty } & \multicolumn{2}{|c|}{ Lot of difficulty } \\
\hline & $\mathrm{N}$ & $\%$ & $\mathrm{~N}$ & $\%$ & $\mathrm{~N}$ & $\%$ & $\mathrm{~N}$ & $\%$ \\
\hline Joining in community activities & 41 & 1.1 & 2 & 0.05 & 48 & 13.3 & 26 & 7.2 \\
\hline $\begin{array}{l}\text { Living with dignity because of attitudes } \\
\text { /actions of others in society }\end{array}$ & 20 & 0.5 & 0 & 0 & 36 & 10.0 & 3 & 0.8 \\
\hline $\begin{array}{l}\text { Living with dignity because of barriers } \\
\text { or hindrance in the world around }\end{array}$ & 20 & 0.5 & 1 & 0.03 & 21 & 5.8 & 3 & 0.8 \\
\hline $\begin{array}{l}\text { Doing things yourself for relaxation } \\
\text { or pleasure }\end{array}$ & 18 & 0.5 & 0 & 0 & 29 & 8.0 & 3 & 0.8 \\
\hline \multicolumn{9}{|l|}{ Health concerns } \\
\hline $\begin{array}{l}\text { Spending time on a health condition or } \\
\text { its consequence }\end{array}$ & 20 & 0.5 & 0 & 0 & 21 & 5.8 & 4 & 1.1 \\
\hline $\begin{array}{l}\text { Emotionally affected by } \\
\text { health condition }\end{array}$ & 20 & 0.5 & 0 & 0 & 20 & 5.6 & 2 & 0.6 \\
\hline $\begin{array}{l}\text { Health being a drain on financial } \\
\text { resources of the family }\end{array}$ & 21 & 0.6 & 1 & 0.03 & 30 & 8.3 & 8 & 2.2 \\
\hline $\begin{array}{l}\text { How much of a problem did you have } \\
\text { due to a health condition }\end{array}$ & 19 & 0.5 & 0 & 0 & 29 & 8.0 & 3 & 0.8 \\
\hline
\end{tabular}

Table 4. Comparison of visual impairment based on visual acuity measurement and self-reported difficulty in vision among those aged $\geq 40$ years

\begin{tabular}{|c|c|c|c|c|c|c|}
\hline \multirow[t]{2}{*}{ Visual acuity category } & \multicolumn{2}{|c|}{$\begin{array}{l}\text { No difficulty in } \\
\text { seeing }(2276)\end{array}$} & \multicolumn{2}{|c|}{$\begin{array}{c}\text { Some degree of difficulty } \\
\text { in seeing }(3463)\end{array}$} & \multicolumn{2}{|c|}{$\begin{array}{c}\text { Total } \\
N=5739\end{array}$} \\
\hline & $\mathrm{N}$ & $\%$ & $\mathrm{~N}$ & $\%$ & $\mathrm{~N}$ & $\%$ \\
\hline No visual impairment & 1684 & 43.5 & 2186 & 56.5 & 3870 & $100 \%$ \\
\hline Mild visual impairment & 278 & 35.5 & 504 & 64.5 & 782 & $100 \%$ \\
\hline Moderate visual impairment & 282 & 31.8 & 604 & 68.2 & 886 & $100 \%$ \\
\hline Severe visual impairment or blind & 33 & 16.4 & 169 & 84.1 & 201 & $100 \%$ \\
\hline
\end{tabular}

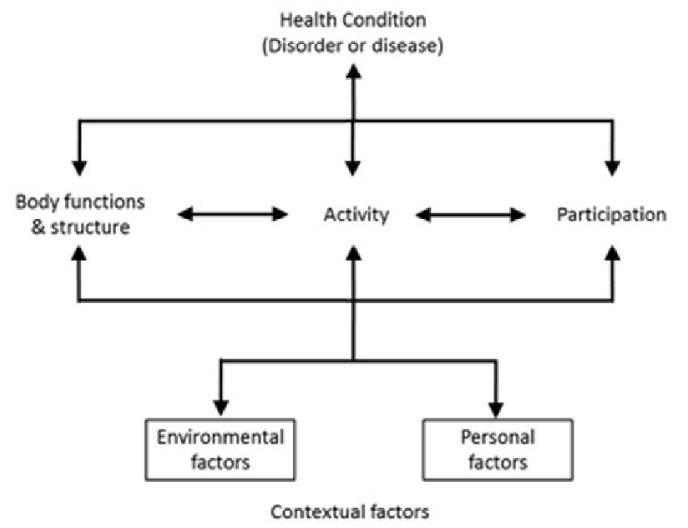

Figure 1. Contextual framework of International Classification of Functioning, Disability and Health.

\section{Discussion}

A recent review of the published literature on disability in Sri Lanka found significant gaps in disability research [13]. The review highlighted the fact that all major recommendations in the World Report on Disability were pertinent to Sri Lanka and it was suggested that a National Survey on disability was desirable [13]. The review explored the capability of an instrument to measure the prevalence of disability and concluded that none of the existing instruments measured population based prevalence accurately. This evidence prompted the use of the short set of WG questions with additional items related to activity limitation and social participation in the present survey.

The study found that $3.8 \%$ of the population aged $\geq 18$ years in Sri Lanka reported disability. The World Report on Disability gives a prevalence of $12.9 \%$ based on the 
World Health Survey (WHS) data [2]. The WHS looked at 16 domains. The present study highlights the difference in prevalence data depending on the survey methodology used and the difficulties in planning programs. Difficulty in mobility was the commonest disability followed by difficulty in vision. "Difficulty seeing" was the commonest domain leading to some degree of functional difficulty. An earlier study in Sri Lanka assessed physical disability among a comparable adult age group and reported a prevalence of $4.2 \%$ (95\% CI: 3.5-5.1) [30]. Another study from southern India reported a prevalence of $4.7 \%$ for mobility-related disability and $2.1 \%$ for vision-related severe grades of disability [31]. It is very difficult to strictly compare the estimates from these studies because different assessment methods were used. One of the reasons why vision-related disability may have been reported by a large number of participants in the present study is because respondents were aware that this was primarily an eye survey and so some may have emphasised their eye problems, possibly that was why about $56 \%$ of persons 40 years and older with no visual impairment reported visual difficulty. However, a disability survey in Uganda also reported vision as the commonest reported disability [9].

In the present study, we were able to validate the findings of the eye examination against the WG question related to vision in those aged $\geq 40$ years showing that $84.1 \%$ of those with severe visual impairment or blindness reported some degree of problem with vision. Similar findings were observed in Cameroon and India earlier [32]. In this study however the tool identified a large number of 'false positives' as over $56 \%$ of those for whom no visual impairment was diagnosed based on visual acuity measurement reported some problems with seeing. As this comparison was undertaken on those aged $\geq 40$ years it is possible that a large number had reported problems in near vision. As the WG short set does not differentiate between distance and near vision, it is difficult to comment on this finding.

Our findings on socio-demographic associations of disability are similar to those reported from other disability prevalence studies conducted in low and middle income countries (LMIC). An increase in the prevalence of disability with increasing age $[16,19,31,32]$ has been reported from a large number of studies, including those undertaken in LMIC. This is because many impairments causing disability are age-related, such as visual or hearing impairment or restriction of mobility. In LMICs, females and those with lower levels of literacy are also more likely to report disability $[15,18,19,31,32]$. This could be attributed to the poorer access to health care experienced by women in LMICs, particularly in South Asia. In Sri Lanka, since women have a significantly higher life expectancy compared to males, they constitute a greater proportion of the aged who are at a higher risk of functional disability.
The measurement of disability helps to identify the magnitude of disability and the number of people needing services for their disability and the characteristics and location of marginalized population groups. This helps in planning need-based policies, and to target specific interventions to redress gaps in relation to health and social inclusion of PWD. From a health perspective, many studies have shown a strong association between poorer health status and access to health services amongst PWD [24,26,28,34-37]. PWD have been reported to have significantly higher rates of chronic disease such as diabetes and depression compared to those without disability [28], and disabled women are more disadvantaged than men [28]. Ensuring inclusive health [38] is therefore, critical to improving the health of PWD and achieving universal health coverage [39].

From a social development perspective, it is now widely recognized that there is a strong association between disability and poverty [25] and that the inclusion of PWD is critical to achieving sustainable development goals [40]. It is therefore essential that disability statistics are effectively used to develop a two-pronged strategy that targets the specific public health concerns of PWD and sustainable development initiatives that promote equal participation of PWD in society. The evidence from the present study could help in establishing the baseline for Sri Lanka to monitor progress towards the sustainable development goals and the WG short set can be used in the 2021 census to explore temporal trends in disability.

Study limitations: the less than $80 \%$ response rate of the enumerated persons most of whom were absent, may have overestimated the prevalence of functionally difficulty and disability, as persons with disability may be likely to stay back at home for the survey

\section{Acknowledgements}

We acknowledge the support from the members of the Steering Committee, the Sri Lanka College of Ophthalmologists, the Vision2020 Secretariat, Ministry of Health and Family Welfare, Sri Lanka, Sightsavers Country Office, Sri Lanka and all the supervisors and field investigators (Madhuni Wijepala, Subhashini Deshappriya, Rasika Damayanthi, Dinusha Sandamali, Ashanti de Silva, Chaturika Madushani, Menaka Rathnayake, Madusha Priyadarshini, Nadeesha Dilhani, Gaya Shanthi) and data entry operators (Sunethra Thennakoon, Kumuduni Sriyalatha) who worked with great diligence in collecting the data from the survey participants. We thank all the survey participants for giving us the time and opportunity to interact with them to collect critical data.

We would like to thank Sightsavers for financial support of the overall study and CBM for financial contributions to the disability component of the survey. 


\section{Conflicts of Interest}

All authors declare that they do not have any conflicts of interest.

\section{References}

1. Leonardi M, Bickenbach J, Ustun TB, Kostanjsek N Chatterji C. The definition of disability: what is in a name? Lancet 2006; 368: 1219-21.

2. World Health Organization and World Bank. World Report on Disability. WHO, Geneva 2011: 1-354. http:// www.who.int/disabilities/world_report/2011/report.pdf. Accessed 10th June 2016.

3. Bickenbach JE, Chatterji C, Badley EM, Ustun TB. Models of disablement, universalism and the international classification of impairments, disabilities and handicaps. Soc Sci Med 1999; 48: 1173-87.

4. Ustun TB, Chatterji C, Bickenbach J, Kostanjsek N, Schneider M. The International Classification of Functioning, Disability and Health: a new tool for understanding disability and health. Disabil Rehabil 2003; 25: $565-71$

5. Seelman KD. The World Health Organization/ World Bank's First World Report on Disability. Int J Telerehab 2011; 3: 11-13.

6. Goujon N, Devine A, Baker SM, et al. A comparative review of measurement instruments to inform and evaluate effectiveness of disability-inclusive development. Disabil Rehabil 2014; 36: 804-12.

7. Trani JF, Babulal GM, Bakhshi P. Development and Validation of the 34-Item Disability Screening Questionnaire (DSQ-34) for Use in Low and Middle Income Countries Epidemiological and Development Surveys. PLoS One 2015; 10: $\mathrm{e} 0143610$

8. Sabariego C, Oberhauser C, Posarac A, et al. Measuring disability: comparing the impact of two data collection approaches on disability rates. Int J Environ Res Public Health 2015; 12: 10329-51.

9. Bachani AM, Galiwango E, Kadobera D, et al. A new screening instrument for disability in low-income and middle-income settings: application at the Iganga-Mayuge Demographic Surveillance System (IM-DSS), Uganda. BMJ Open 2014; 4(12): e005795

10. Ustün TB, Chatterji S, Kostanjsek N, et al. Developing the World Health Organization Disability Assessment Schedule 2.0. Bull World Health Organ. 2010; 88: 815-23.

11. Marella M, Busija L, Islam FM, et al. Field-testing of the rapid assessment of disability questionnaire. BMC Public Health 2014; 14: 900.

12. Madans JH, Loeb ME, Altman BA. Measuring disability and monitoring the UN Convenetion on the Rights of Persons with Disabilities: the work of the Washington Group on Disability Statistics. BMC Public Health 2011; 11(Suppl 4): S4.
13. Peiris-John RJ, Attanayake S, Daskon L, Wickremasinghe AR, Ameratunga S. Disability studies in Sri Lanka: priorities for action. Disabil Rehabil 2014; 36: 1742-8.

14. Madans JH, Loeb M. Methods to improve international comparability of census and survey measures of disability. Disabil Rehabil 2013; 35: 1070-3.

15. Mitra S, Sambamoorthi U. Disability prevalence among adults: estimates for 54 countries and progress towards a global estimate. Disabil Rehabil 2014; 36: 940-7.

16. Ayazi T, Lien L, Eide AH, Jenkins R, Albino RA, Hauff E. Disability associated with exposure to traumatic events: results from a cross-sectional community survey in South Sudan. BMC Public Health 2013; 13: 469.

17. Guzman JM, Salazar EG. Disability and rehabilitation in Mexico. Am J Phys Med Rehabil 2014; 93(1 Suppl 1): S36-8.

18. Danquah L, Polack S, Brus A, et al. Disability in postearthquake Haiti: prevalence and inequality in access to services. Disabil Rehabil 2015; 37: 1082-9.

19. Cherry N, Chowdhury M, Haque R, McDonald C, Chowdhury Z. Disability among elderly rural villagers: report of a survey from Gonoshasthaya Kendra, Bangladesh. BMC Public Health 2012; 12: 379.

20. Census 2001, Sri Lanka. http://www.statistics.gov.lk/ pophousat/PDF/Disability/p11d1\%20Disabled $\% 20$ persons\%20by\%20Sex\%20and\%20District.pdf. Accessed 13th June 2016.

21. World Health Organization. http://www.who.int/healthinfo/ survey/en. Accessed 16th June 2016.

22. United Nations Social Development Division, Economic and Social Commission for Asia and the Pacific, Bangkok 2016. Disability at a Glance 2015:1-190. http:// www.unescap.org/sites/default/files/SDD\% 20Disability\%20Glance\%202015_Final.pdf. Accessed 10th June 2016.

23. Durocher J, Lord J, Defranco A. Disability and global development. Disability Health 2012; 5: 132-5.

24. Shrestha S, Shreshtha NK, Deepak S. A Community Assessment of Poverty and Disability among specific rural population groups in Nepal. Asia Pacific Disab Rehab $J$ 2009; 20: 83-98.

25. Kampen MV, Zijverden IMV, Emmett T. Reflections on poverty and disability: A review of literature. Asia Pacific Disab Rehab J 2008; 19: 19-37.

26. Trani JF, Browne J, Kett M, et al. Access to health care, reproducctive health and disability: a large scale survey in Sierra Leone. Soc Sci Med 2011; 73: 1477-89.

27. Eide $\mathrm{AH}$, Mannan $\mathrm{H}$, Khogali $\mathrm{M}$ et al. Perceived barriers for accessing health services among individuals with disability in four African countries. PLoS One 2015; 10: e0125915.

28. Murthy GV, John N, Allagh K, Sagar J, Kamalakannan S, Ramachandra SS. Access to health care and employment status of people with disabilities in South India, the SIDE (South India Disability Evidence) Study. BMC Public Health 2014; 14: 1125. 
29. Gona JK, Xiong T,Muhit MA, Newton CR, Hartley S. Identification of people with disabilities using participatory rural appraisal and key informants: A pragmatic approach with action potential promoting validity and low cost. Disabil Rehabil 2010; 32: 79-85.

30. Weerasinghe IE, Fonseka P, Dharmaratne SD, Jayatilake JAMS. Prevalence of physical disability among urban community-dwelling adults in Sri Lanka. J Disabil CBR Inclusive Development 2015; 26: 65-91.

31. Ramachandra SS, Allagh KP, Kumar H, Grills N, et al. Prevalence of disability among adults using Rapid Assessment of disability tool in a rural district of South India. Disabil Health J 2016; 9: 624-31.

32. Mactaggart I, Kuper H, Murthy GVS, Oye J, Polack S. Measuring disability in population-based surveys: The interrelationship between clinical impairments and reported functional limitations in Cameroon and India. PLoS One 2016; 11: e0164470.

33. Emerson E, Madden R, Graham H, Llewellyn G, Hatton C, Robertson J. The health of disabled people and the social determinants of health. Public Health 2011; 125: 145-7.
34. McColl MA. Disability studies at the population level: issues of health service utilization. Am J Occup Ther 2005; 59: $516-26$.

35. Trani JF, Bakhshi P, Noor AA, Lopez D, Mashkoor A. Poverty, vulnerability and provision of health care in Afghanistan. Soc Sci Med 2010; 70: 1745 -55.

36. Lee JE, Kim HR, Shin HI. Accessibility of medical services for persons with disabilities: comparison with the general population in Korea. Disabil Rehabil 2013.

37. Maart S, Jelsma J. Disability and access to health care - a community-based descriptive study. Disabil Rehabil 2014; 36: $1489-93$

38. Maclachlan M, Khasnabis C, Mannan H. Inclusive health. Trop Med Int Health 2012; 17: 139-41.

39. Binagwaho A, Scott KW. Improving the world's health through the post-2015 development agenda: perspectives from Rwanda. Int J Health Policy Manag 2015; 4: 203-5.

40. Tardi R, Njelesani J. Disability and the post-2015 development agenda. Disabil Rehabil 2015; 37: 1496-500. 